\title{
Latissimus dorsi transfer for the treatment of massive tears of the rotator cuff
}

\author{
Manuel Zafra $\cdot$ Pedro Carpintero $\cdot$ Carmen Carrasco
}

Received: 23 December 2007 /Revised: 9 January 2008/Accepted: 10 January 2008 / Published online: 5 April 2008

(C) Springer-Verlag 2008

\begin{abstract}
The objective of this paper was to determine the outcome of the transfer of the latissimus dorsi tendon in patients with massive irreparable rotator cuff tears. Eighteen patients of mean age 54 years (range $37-72$ years) with massive irreparable rotator cuff tears were studied. The mean follow-up was 28 months (range 12-58 months). The postoperative Constant score was higher by an average of 21.15 points compared to the preoperative score $(P=0.002)$; $88.8 \%$ of patients reported significant pain relief and improved mobility, particularly on external rotation. Postoperative resting antero-posterior radiography in neutral rotation revealed a mean 3.2-mm depression of the humeral head, due to the tenodesis effect of tendon transfer, thus, increasing the deltoid lever arm. These clinical results suggest that latissimus dorsi transfer is a useful surgical technique for treating massive irreparable postero-superior tears of the rotator cuff in young and/or active patients, providing significant pain relief and improved shoulder strength.
\end{abstract}

Résumé Déterminer le devenir des transferts du grand dorsal réalisé chez les patients avec rupture massive irréparable de la coiffe des rotateurs. 18 patients d'âge moyen 54 ans (allant de 37 à 72 ans) avec une rupture massive irréparable de la coiffe des rotateurs. Le suivi moyen était de 28 mois (allant de 12 à 58 mois). le score de Constant post-opératoire était amélioré en moyenne de 21,15 points par rapport au score préopératoire $(P=0,002)$; $88,8 \%$ des patients rapportaient une amélioration significative de la douleur et de la mobilité en particulier sur la

M. Zafra $\cdot$ P. Carpintero $(\bowtie) \cdot$ C. Carrasco

Orthopaedic, University Hospital Reina Sofia,

Avenue Menendez Pidal S/N,

Cordoba 14004, Spain

e-mail: pcarpinterob@medynet.com rotation externe. Les radios postopératoires de face au repos, en position neutre, montraient un abaissement moyen de $3,2 \mathrm{~mm}$ de la tête humérale dû à l'effet ténodèse du transfert tendineux augmentant ainsi le bras de levier du deltoïde. Ces résultats cliniques suggèrent que le transfert $\mathrm{du}$ grand dorsal est une technique efficace pour le traitement des ruptures massives de la coiffe des rotateurs chez les patients jeunes et/ou actifs amenant une réduction significative de la douleur et une augmentation de la force de l'épaule.

\section{Introduction}

Rotator cuff tears are frequent after a certain age, occurringaccording to Bigliani et al. [4] - in 39\% of people over 60 . They appear to become more common as the body ages [18] and, in $80 \%$ of cases, are progressive [4]. However, it is not known why some tears are symptomatic and others are not.

The treatment of choice in symptomatic rotator cuff tears is the suturing of the tendon and reattachment to bone, through either open or arthroscopic surgery [4, 5, 7, 10, 23]. Unfortunately, over $30 \%$ of tears [21] are too large (over 5 $\mathrm{cm})$ to be repaired, since direct attachment of the tendon to the proximal humerus is technically impossible, despite the mobilisation of the remaining soft tissue. Chronic tears may give rise to tendon retraction, atrophy and fatty degeneration of the affected muscle [13], leading to impaired muscle quality and, often, to defective contraction, which renders bone reattachment ineffective. In such cases, the therapeutic options include arthroscopic debridement [10], acromioplasty [17], biceps tenodesis [20], cuff fixation to avoid progression [5], tuberoplasty [9], tendon transfer $[1-3,6,11,12,15,19,21,22]$ and tendon graft. 


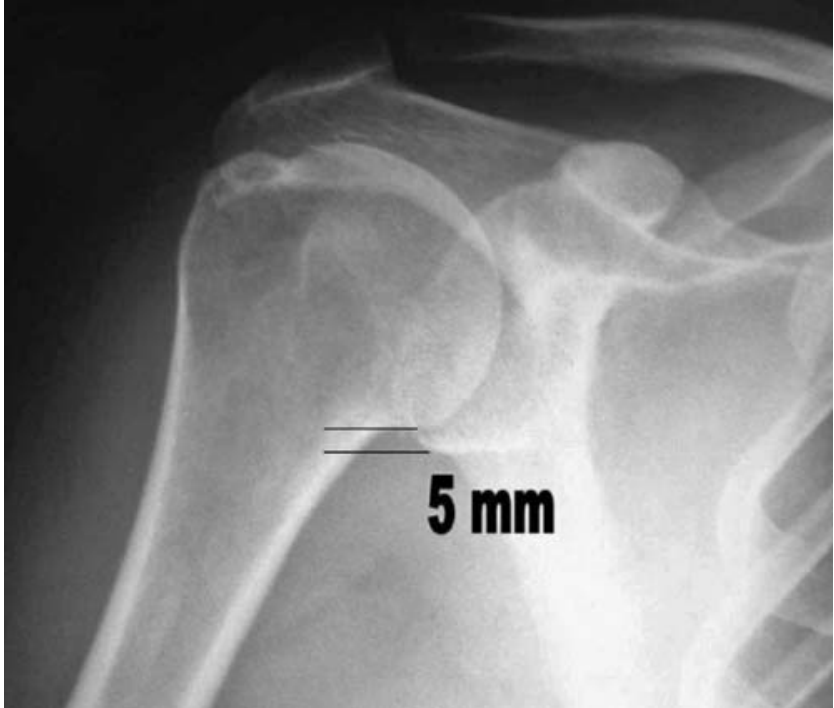

Fig. 1 Preoperative antero-posterior radiograph showing the interruption of Shenton's line and migration of the humeral head

The results obtained using these techniques vary considerably, and the optimal management of massive irreparable rotator cuff tears remains controversial; the treatment of choice will be governed by a number of factors, including the type of tear and the patient's age, symptoms and functional demands.

One possible approach to rotator cuff tears is tendon transfer, which is widely used in the treatment of the increasingly rare obstetric brachial plexus palsy, particularly involving $\mathrm{C} 5$, with congruent glenohumeral joint [16]. In 1988, Gerber et al. [12] described the first transfer of the latissimus dorsi tendon in the treatment of irreparable rotator cuff tears. This paper presents a retrospective study of patients undergoing latissimus dorsi transfer for massive irreparable rotator cuff tears, analysing the results obtained and seeking a biomechanical explanation for the efficacy of this approach.

\section{Patients and methods}

This retrospective study included 18 patients (13 female, 5 male) treated between June 2000 and March 2005. Preoperative and postoperative clinical examinations were performed, and the Constant test [8] was used to assess pain, mobility and strength. To check for possible osteoarthritis and proximal migration of the humeral head, anteroposterior radiography of the shoulder, in neutral rotation, was performed preoperatively and again at the end of the follow-up period. The presence of proximal migration was shown by an interrupted Shenton's line extending from the glenoid rim to the humeral neck; migration was measured in $\mathrm{mm}$ up the humeral neck rather than in the subacromial space, which might have been modified by subacromial decompression (Figs. 1 and 2). Only one patient displayed mild arthrosis, with osteophytes less than $3 \mathrm{~mm}$ and no evidence of joint-line irregularities or subchondral sclerosis. Magnetic resonance imaging (MRI) was also performed preoperatively to check for tendon retraction, atrophy and fatty degeneration of the affected muscle (Fig. 3). Preoperative examination included the Napoleon test to rule out subscapularis tears; the findings were confirmed by MRI. Patients with subscapularis tears were excluded from the study.

Surgery was performed by the same team in all cases, using the technique described by Gerber et al. [12]. The patients, none of whom had undergone previous surgery, received prophylactic antibiotic therapy using a secondgeneration cephalosporin, which was continued until 24 hours post-operation. The patient was placed in the lateral decubitus position, and an axillary roll was placed to protect against nerve-vessel compression in the contralateral arm. The affected arm, shoulder and dorsal periscapular region were draped free. The rotator cuff was first exposed through an antero-superior approach, and the latissimus dorsi through a dorsolateral approach along the line of the muscle-tendon junction. All shoulders had tears involving both the supraspinatus and the infraspinatus. The subscapularis and long head of the biceps were unaffected in all patients.

The deltoid was detached from the acromion and an anterior acromioplasty was performed. The latissimus dorsi was dissected from the point on the scapula where separation from the teres major was clearest, in an axillary direction as far as the osseus attachment on the humerus. Forced internal rotation and good separation were essential when dissecting tendon from bone, in order to avoid

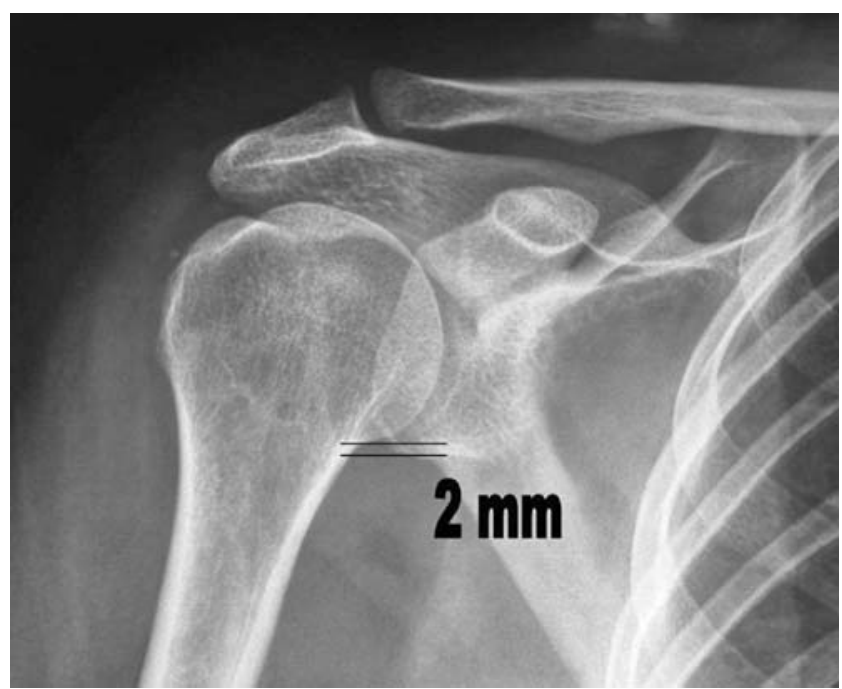

Fig. 2 Postoperative radiograph showing depression of the humeral head after tendon transfer 


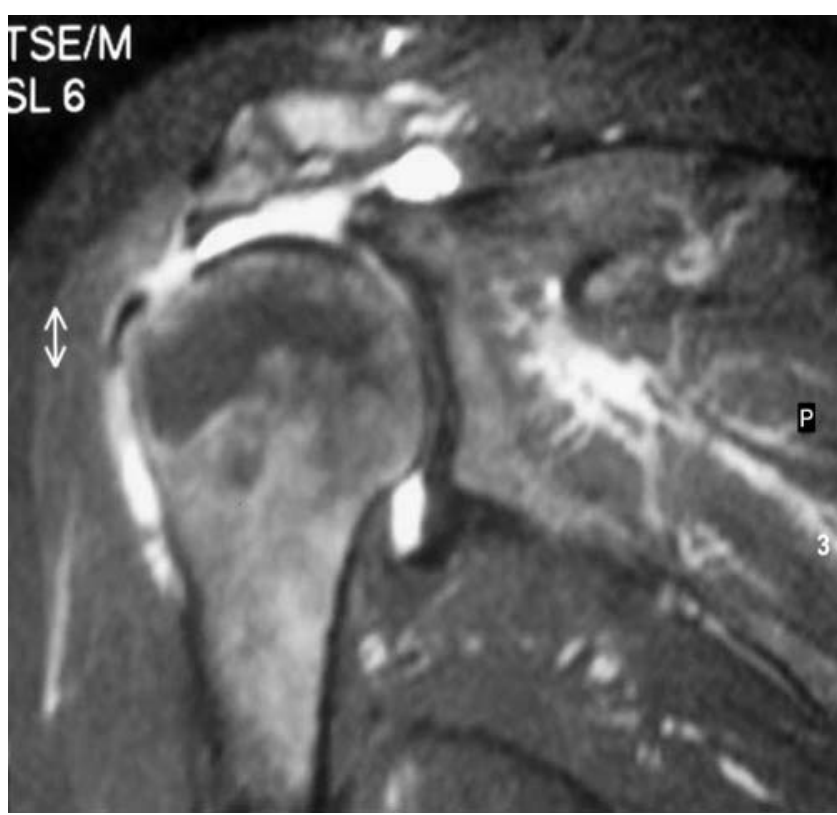

Fig. 3 Shoulder magnetic resonance imaging (MRI). Tendon tear and retraction, atrophy and fatty degeneration of the supraspinatus muscle

neurovascular injury. Non-resorbable sutures were placed along each edge to initiate muscle-tendon fixation; braided sutures were used to fix the tendon, in order to avoid possible subsequent detachment. The muscle was broadly dissected to ensure good freedom and mobility (Fig. 4). The neurovascular pedicle was not identified in most cases. The interval between the deltoid and the infraspinatus fossa was dissected, and the transfer was then passed through for reattachment to the greater tuberosity and the subscapularis tendon. Sutures were performed first on one side and then on the other, in order to avoid twisting the tendon during transfer. The tendon was anchored to the bone and to the subscapularis using non-resorbable transosseous sutures. It was not always possible to anchor the tendon to the retracted edges of the supraspinatus. The deltoid was then reattached to the acromial border with transosseous sutures, and a suction drain was placed posteriorly for a minimum of 48 hours.

Postoperatively, the arm was immobilised in mild abduction $\left(20-25^{\circ}\right)$ for 6 weeks. Passive physical therapy was started after 4 weeks, and active therapy 6 weeks, after the removal of immobilisation. The recovery period varied, but was at least 6 months.

Statistical analysis of the data was performed using the Wilcoxon non-parametric test for paired data (using confidence interval 95\%).

\section{Results}

The 18 patients were followed up over a mean interval of 28 months (range 12 to 58 months) following latissimus dorsi transfer. The average patient age was 54 years (range 37 to 62 years).

Fig. 4 Operative photograph showing a free, mobile latissimus dorsi muscle-and-tendon unit ready for transfer

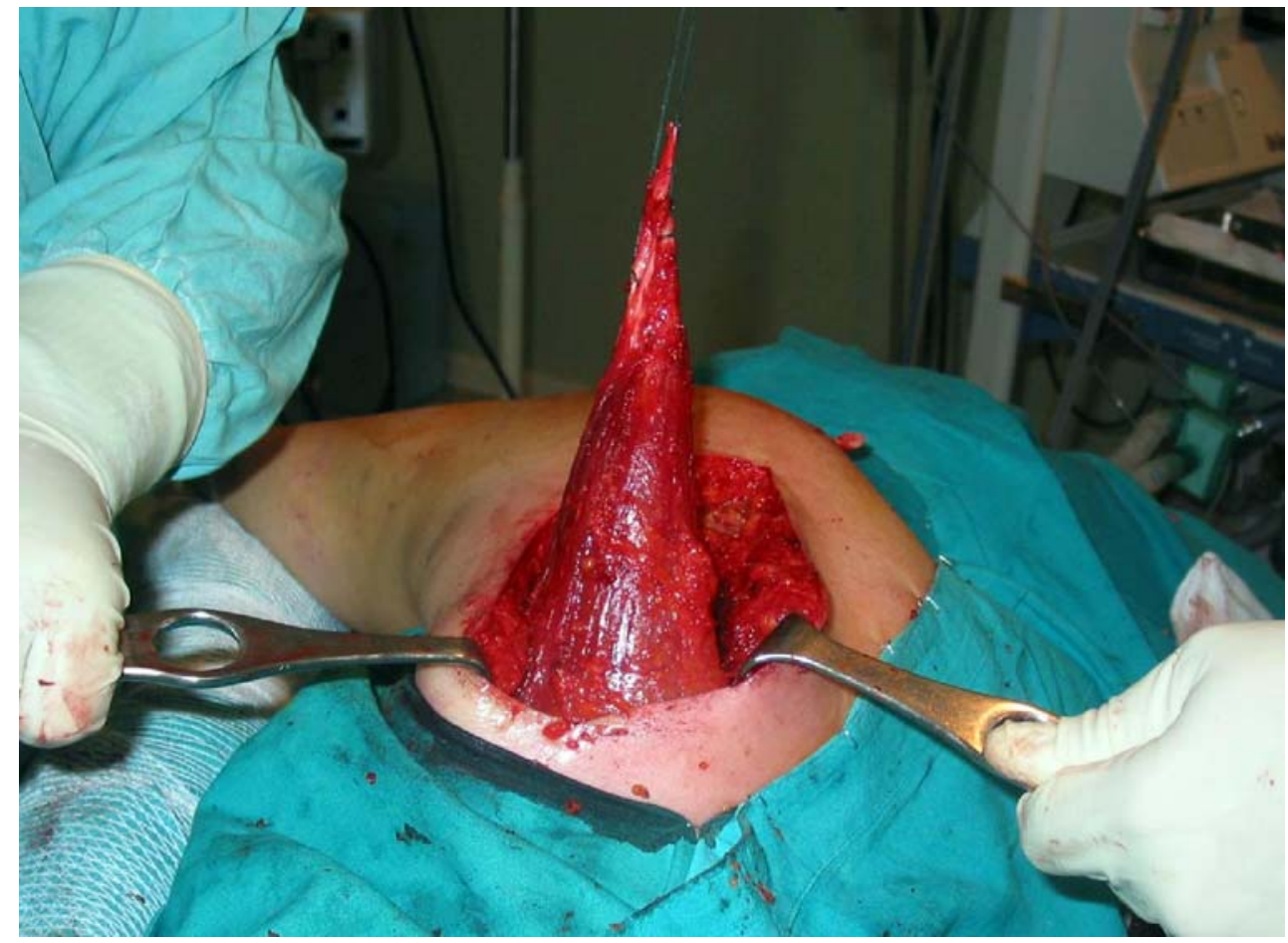


Pain

The mean preoperative pain score on the Constant scale was 6.04 points (range $4.2-8$ points), while the mean postoperative score was 12.9 points (range $8.3-14.3$ points) $(P=0.018)$. Preoperative pain was reported as intense in 11 cases and moderate in 7 patients. The postoperative pain was intense in 2 patients, moderate in 2, mild in 6 and nonexistent in 8 patients. Overall, 16 patients $(88.8 \%)$ reported pain relief (Table 1).

\section{Mobility}

The preoperative mean flexion was $93^{\circ}$ (range $40^{\circ}-160^{\circ}$ ), while the postoperative mean flexion was $139^{\circ}\left(60^{\circ}-180^{\circ}\right)$, giving a mean improvement of $46^{\circ}(P=0.003)$. Abduction increased from $85^{\circ}$ (range $30^{\circ}-130^{\circ}$ ) to $125^{\circ}$ (range $40^{\circ}-$ $\left.160^{\circ}\right)$, with a mean improvement of $40^{\circ}(P=0.025)$, and external rotation rose from $8^{\circ}$ (range $-10^{\circ}-18^{\circ}$ ) to $30^{\circ}$ (range $\left.0^{\circ}-40^{\circ}\right)$, an improvement of $22^{\circ}(P=0.009)$.

\section{Strength}

The mean preoperative strength was $13 \mathrm{~kg}$ (range 9-15 kg), rising postoperatively to $17 \mathrm{~kg}$ (range $12-21 \mathrm{~kg}$ ), an improvement of $4 \mathrm{~kg}(P=0.001)$.

The mean preoperative Constant score was 49.10 (range $30-64)$, which increased postoperatively to 70.25 (55-85), a mean increase of 21.15 points $(P=0.002)$.

Patient subjective evaluation was very good in 9 cases, good in 5, poor in 2 and very poor in 2.

Antero-posterior radiography of the shoulder, in neutral rotation, showed a mean proximal migration of the humeral head of $5 \mathrm{~mm}$ (range 1-7 mm); postoperatively, the mean proximal migration was $1.8 \mathrm{~mm}$ (range $0-4 \mathrm{~mm}$ ) $(P=0.001)$, a decrease of $3.2 \mathrm{~mm}$.

Complications arose in two cases: acute staphylococcus infection, requiring surgical drainage, debridement and intravenous antibiotic therapy for 3 weeks; and donor-site haematoma, requiring drainage and reattachment of the suction system for 48 hours.
During follow-up, one patient presented spontaneous rupture of the biceps tendon 4 weeks post-surgery (treated conservatively). Another patient presented retearing of the transferred tendon 6 weeks post-surgery at the start of active physical therapy; the patient reported intense pain and a tearing sensation in the shoulder. This was initially treated by conservative means, but due to persistent pain, arthroscopy was performed 3 months later; tearing and detachment of the tendon was apparent. Arthroscopic debridement provided mild pain relief, although the pain persisted and shoulder mobility was similar to that reported prior to tendon transfer. No cases of deltoid detachment were found.

\section{Discussion}

Good results were reported for tendon or muscle transfer in the treatment of massive rotator cuff tears as early as 1985, when Apoil and Augereau [3] obtained a 75\% success rate with deltoid flap transfers. However, use of the deltoid flap to cover cuff tears is by no means an ideal approach, since it involves an impairment of the residual abduction/flexion lever mechanism. Vandenbussche et al. [19] also reported good results with this technique, with an $80 \%$ improvement in the mean absolute Constant score value, and subjective results of $89 \%$ of satisfied or very satisfied patients after a mean follow-up of 10.5 years. In 1988, Gerber et al. [12] reported on the first use of latissimus dorsi transfer in irreparable supraspinatus-infraspinatus tears, with good clinical outcomes [11]; since then, a number of studies have reported on the use of this tendon $[1,2,15,21,22]$ and, to a lesser extent, of the teres major [6].

The results obtained here indicate that latissimus dorsi transfer is a good treatment option for selected patients with massive rotator cuff tears: the Constant test score improved significantly, rising by 21.15 , from 49.2 preoperatively to 70.4 postoperatively; there was significant pain relief in $88.8 \%$ of patients; mobility was considerably enhanced (by $46^{\circ}$ in flexion, by $40^{\circ}$ in abduction and by $22^{\circ}$ in external rotation). Although the shoulder strength in all patients failed to attain
Table 1 Results for the latissimus dorsi transfer

\begin{tabular}{lccc}
\hline & Preoperative & Postoperative & $P$ value \\
\hline Pain & $6.04($ range $4.2-8)$ & $12.9($ range $8.3-14.3$ & .018 \\
Mobility & $93^{\circ}\left(\right.$ range $\left.40^{\circ}-160^{\circ}\right)$ & $139^{\circ}\left(\right.$ range $\left.60^{\circ}-180^{\circ}\right)$ & .003 \\
Flexion & $85^{\circ}\left(\right.$ range $\left.30^{\circ}-130^{\circ}\right)$ & $125^{\circ}\left(\right.$ range $\left.40^{\circ}-160^{\circ}\right)$ & .025 \\
Abduction & $8^{\circ}\left(\right.$ range $\left.-10^{\circ}-18^{\circ}\right)$ & $30^{\circ}\left(\right.$ range $\left.0^{\circ}-40^{\circ}\right)$ & .009 \\
External rotation & $13 \mathrm{~kg}($ range $9-15 \mathrm{~kg})$ & $17 \mathrm{~kg}($ range $12-21 \mathrm{~kg})$ & .001 \\
Strength & 49.10 points & 70.25 points $($ range $55-85$ points $)$ & .002 \\
Constant test & $($ range $30-64$ points) & & .001 \\
Migration humeral head & 5 mm (range $1-7 \mathrm{~mm})$ & $1.8 \mathrm{~mm}($ range $0-4 \mathrm{~mm})$ & \\
\hline
\end{tabular}


the values recorded for the healthy contralateral shoulder, there was, nonetheless, an improvement of $4 \mathrm{~kg}$.

However, given that this is a complex, open-surgery technique followed by a troublesome postoperative period and a long stretch of physiotherapy - at least 6 months - it is, perhaps, most suitable for young, active patients, offering them significant pain relief and improved strength. In older or more sedentary patients, less aggressive approaches with a shorter and less tiresome convalescence may be preferable and still provide selective pain relief; such approaches include tubercleplasty, arthroscopic debridement and tenodesis or tenotomy of the long head of the biceps.

Biomechanically, contraction of the deltoid due to loss of the supraspinatus muscle prompts a proximal migration of the humeral head, especially in the first few degrees of abduction, as shown by Burkhart [5] and Yamaguchi et al. [24]. The transferred latissimus dorsi, a powerful muscle innervated by the thoracodorsal nerve ( $5-\mathrm{C} 6)$, becomes an external rotator for the shoulder, following the direction and mimicking the action of the infraspinatus. It also depresses the humeral head, increasing the deltoid lever arm, which might account for improved abduction and flexion of the shoulder joint. Depression of the humeral head occurs in the first place as a result of tenodesis, apparent here in the resting shoulder. However, Aoki et al. [2] report that the electromyography (EMG) examination of patients undergoing active physiotherapy confirms the contraction of the transferred tendon already apparent on palpation; this is likely to exert a further depressor effect on the humeral head, although the extent of depression was not tested here.

During follow-up, only one patient displayed mild osteoarthritis, already noted at preoperative examination. This agrees with the findings of Gerber [11], who reported no evidence of degenerative change following latissimus dorsi transfer; by contrast, Aoki et al. [2] noted the progression of osteoarthritic degeneration in half of the patients undergoing this type of surgery.

Tendon transfer was not performed in patients with the combination of torn supraspinatus, infraspinatus and also subscapularis. Gerber [11] and Aoki et al. [2] advise against this approach when there is subscapularis involvement, although Warner and Parsons [22] report that it may be effective, even in these patients. Aldridge et al. [1] reported mixed results for combined pectoralis major and latissimus dorsi transfer in supraspinatus and subscapularis tears in patients with preoperative flexion and abduction of less than $90^{\circ}$; only half of the patients undergoing surgery achieved over $90^{\circ}$ flexion. In elderly patients displaying less than $80^{\circ}$ abduction, even though the subscapularis remains intact, the success of latissimus dorsi transfer is not guaranteed. As a general rule, in patients with involvement of all tendons, and in patients over 70 years of age with supraspinatus and infraspinatus tears but intact subscapularis who are unable to raise their arm over $80^{\circ}$, inverted arthroplasty may be the most suitable approach for attaining over $90^{\circ}$ elevation $[2,11]$.

Complications are not common using this tendon transfer technique $[2,11,14,22]$. In our study, one patient with acute staphylococcus infection required surgical drainage, debridement and intravenous antibiotic therapy for 3 weeks; all non-resorbable sutures and anchors had to be removed, leading to failure of the transfer. The patient displayed significant pain relief, but no improvement in strength. A second patient had donor-site haematoma, requiring drainage and reattachment of the suction system for 48 hours. Although the clinical outcome was good, meticulous dissection and haemostasis of the latissimum dorsi is clearly essential.

During follow-up, one patient presented spontaneous rupture of the long head of the biceps tendon 30 days postsurgery; this was treated conservatively, with non-steroidal anti-inflammatory drugs (NSAIDs) and rest for a few days. The clinical outcome was good, with complete pain relief and improved shoulder strength, marred only by some aesthetic deterioration due to the biceps tear. One patient $(5.5 \%)$ presented retearing of the transferred tendon 6 weeks post-surgery at the start of active physical therapy. This complication was reported by Warner and Parsons [22] in $17 \%$ of patients and by Aoki et al. [2] in $8.3 \%$ of patients; other reports make no mention of it $[1,12,15]$. The tearing of this tendon, despite careful initial fixation of the muscle-and-tendon unit and subsequent suturing to the humeral head and the subscapularis, was probably due to the thinness of the transferred tendon and to the difficulty in gaining firm anchorage to soft tissues and to the humeral head. The outcome was very poor, with no pain relief and no improvement in mobility.

No cases of deltoid detachment [14] were found in the patients studied here. This may be due to the small number of cases studied, or to the fact that we are usually very careful when reattaching onto the acromion, using transosseous sutures and immobilising the arm for 6 weeks after surgery; most reported detachments take place during this period.

In view of the good clinical results obtained here, tendon transfer would seem to be a good therapeutic choice for certain patients - particularly young, active subjects - with irreparable rotator cuff tears involving the supraspinatus and infraspinatus, but not the subscapularis. In these patients, tendon transfer provides pain relief and a varying degree of improvement in shoulder strength.

\section{References}

1. Aldridge JM 3rd, Atkinson TS, Mallon WJ (2004) Combined pectoralis major and latissimus dorsi tendon transfer for massive rotator cuff deficiency. J Shoulder Elbow Surg 13:621-629 
2. Aoki M, Okamura K, Fukushima S, Takahashi T, Ogino T (1996) Transfer of latissimus dorsi for irreparable rotator-cuff tears. J Bone Joint Surg Br 78:761-766

3. Apoil A, Augereau B (1985) Réparation par lambeau deltoïdien des grandes pertes de substance de la coiffe des rotateurs de l'éépaule. Chirurgie 111:287-290

4. Bigliani LU, Cordasco FA, McIlveen SJ, Musso ES (1992) Operative treatment of massive rotator cuff tears: long-term results. J Shoulder Elbow Surg 1:120-130

5. Burkhart SS (1991) Arthroscopic treatment of massive rotator cuff tears. Clinical results and biomechanical rationale. Clin Orthop Relat Res 267:45-56

6. Celli L, Rovesta C, Marongiu MC, Manzieri S (1998) Transplantation of teres major muscle for infraspinatus muscle in irreparable rotator cuff tears. J Shoulder Elbow Surg 7:485-490

7. Cofield RH, Parvizi J, Hoffmeyer PJ, Lanzer WL, Ilstrup DM, Rowland CM (2001) Surgical repair of chronic rotator cuff tears. A prospective long-term study. J Bone Joint Surg Am 83:71-77

8. Constant CR, Murley AGH (1987) A clinical method of functional assessment of the shoulder. Clin Orthop Relat Res 214:160-164

9. Fenlin JM Jr, Chase JM, Rushton SA, Frieman BG (2002) Tuberoplasty: creation of an acromiohumeral articulation-a treatment option for massive, irreparable rotator cuff tears. J Shoulder Elbow Surg 11:136-142

10. Gartsman GM (1995) Arthroscopic treatment of rotator cuff disease. J Shoulder Elbow Surg 4:228-241

11. Gerber C (1992) Latissimus dorsi transfer for the treatment of irreparable tears of the rotator cuff. Clin Orthop Relat Res 275:152-160

12. Gerber C, Vinh TS, Hertel R, Hess CW (1988) Latissimus dorsi transfer for the treatment of massive tears of the rotator cuff: a preliminary report. Clin Orthop Relat Res 232:51-61

13. Goutallier D, Bernargeau J, Patte D (1989) L'évaluation par le scanner de la trophicité des muscles de la coiffe des rotateurs ayant una rupture tendineuse. Rev Chir Orthop 75(Suppl 1):126-127
14. Gumina S, Di Giorgio G, Perugia D, Postacchini F (2008) Deltoid detachment consequent to open surgical repair of massive rotator cuff tears. Int Orthop 32:81-84

15. Miniaci A, MacLeod M (1999) Transfer of the latissimus dorsi muscle after failed repair of a massive tear of the rotator cuff. A two to five-year review. J Bone Joint Surg Am 81:1120-1127

16. Pagnotta A, Haerle M, Gilbert A (2004) Long-term results on abduction and external rotation of the shoulder after latissimus dorsi transfer for sequelae of obstetric palsy. Clin Orthop Relat Res 426:199-205

17. Rockwood CA, Williams GR, Burkhead WZ (1995) Debridement of degenerative, irreparable lesions of the rotator cuff. J Bone Joint Surg Am 77:857-866

18. Tempelhof S, Rupp S, Seil R (1999) Age-related prevalence of rotator cuff tears in asymptomatic shoulders. J Shoulder Elbow Surg 8:296-299

19. Vandenbussche E, Bensaïda M, Mutschler C, Dart T, Augereau B (2004) Massive tears of the rotator cuff treated with a deltoid flap. Int Orthop 28:226-230

20. Walch G, Madonia G, Pozzi I, Riand N, Lévigne C (1997) Arthroscopic tenotomy of the tendon of the long head of the biceps in rotator cuff ruptures. In: Gazielly D, Gleyze P, Thomas T (eds) The cuff. Elsevier, Amsterdam, pp 350-355

21. Warner JJP (2001) Management of massive irreparable rotator cuff tears: the role of tendon transfer. Instr Course Lect 50:63-71

22. Warner JJP, Parsons IM 4th (2001) Latissimus dorsi tendon transfer: a comparative analysis of primary and salvage reconstruction of massive, irreparable rotator cuff tears. J Shoulder Elbow Surg 10:514-521

23. Yamaguchi K (2001) Mini-open rotator cuff repair: an updated perspective. Instr Course Lect 50:53-61

24. Yamaguchi K, Sher JS, Andersen WK, Garretson R, Uribe JW, Hechtman K, Neviaser RJ (2000) Glenohumeral motion in patients with rotator cuff tears: a comparison of asymptomatic and symptomatic shoulders. J Shoulder Elbow Surg 9:6-11 